\title{
Relaxation of Rat Vascular Muscle by Peripheral Benzodiazepine Modulators
}

Paul Erne, ${ }^{\star}$ Michele Chiesi, ${ }^{\ddagger}$ Stefano Longoni, ${ }^{\star}$ James Fulbright, ${ }^{*}$ and Kent Hermsmeyer*

*Cardiovascular Research Laboratory, Chiles Research Institute, Providence Medical Center and Department of Medicine, Oregon Health Sciences University, Portland, Oregon 97213; and ${ }^{\ddagger}$ Department of Research,

Pharmaceuticals Division, CIBA-Geigy Ltd, 4002 Basel, Switzerland

\begin{abstract}
Effects of peripheral benzodiazepine receptor modulating drugs, Ro 5-4864 and PK 11195, on tension induced by $\mathrm{K}^{+}$and the calcium agonist SDZ 202791 (S isomer), were studied in rat caudal arteries. A significant reduction of tonic phase tension occurred with 30 nM PK 11195 or $3 \mu \mathrm{M}$ Ro 5-4864, but decreases of the initial (first 3 min), phasic contraction were detected only at the highest concentrations of Ro 5-4864 and PK 11195. Protoporphyrin IX, the putative endogenous ligand of the peripheral benzodiazepine receptor, (at 10-100 $\mathrm{nM}$ ) markedly increased the effectiveness of Ro 5-4864 and PK 11195 in reducing phasic contraction. Intracellular calcium localization and distribution in fura-2 loaded single vascular cells were quantitated using a high sensitivity, two-stage microchannel plate, photon-counting (PMI-VIM) camera. Peripheral benzodiazepines reduced intracellular calcium release from centrally located calcium pools, and this decrease of calcium release was potentiated by protoporphyrin IX. The decrease in intracellular calcium activity, which was more pronounced in the central regions where sarcoplasmic reticular elements are numerous, was probably the major mechanism of these vasodilator properties.

Measurements of soluble guanylate cyclase activity also supported the intracellular $\mathrm{Ca}^{2+}$ release mechanism. Under conditions where protoporphyrin IX did not significantly stimulate guanylate cyclase, Ro 5-4864 alone or more effectively in combination with protoporphyrin IX stimulated cGMP production and caused relaxation. Guanylate cyclase forms a possible target for these benzodiazepine modulators, a hypothesis that merits further investigation.
\end{abstract}

\section{Introduction}

The distinction between two different types of benzodiazepine receptors, peripheral- and central-type, has been developing recently (for review see reference 1). The central-type benzodiazepines are often used for their anxiolytic and anticonvulsant properties, demonstrating good correlation between these classical effects of benzodiazepines and binding (2). Although benzodiazepine binding has also been characterized in various peripheral tissues, e.g., kidney (3), lung (4), and liver (5), and associated with the mitochondrial outer membrane (6), a

Address reprint requests to Dr. Kent Hermsmeyer, Chiles Research Institute, Providence Medical Center, 4805 N.E. Glisan, Portland, OR 97213.

Received for publication 12 September 1988 and in revised form 24 January 1989.

J. Clin. Invest.

(C) The American Society for Clinical Investigation, Inc.

0021-9738/89/08/0493/06 \$2.00

Volume 84, August 1989, 493-498 functional correlation in these cases is lacking. Peripheral-type benzodiazepines have been shown to modulate slow action potentials in cardiac tissue $(7,8)$, and notably changes induced by calcium agonists and antagonists (9). However, these cardiac $\mathrm{Ca}^{2+}$ channel effects occurred at concentrations $>3 \mu \mathrm{M}$, suggesting that only a low-affinity binding site of benzodiazepines is coupled to the $\mathrm{Ca}^{2+}$ channel (10). Furthermore, these studies demonstrated that PK 11195, a compound that selectively displaces Ro 5-4864 from its peripheral benzodiazepine binding site, inhibits the effects of both calcium channel agonists and antagonists.

As no peripheral benzodiazepine receptor studies on vascular tissue have been previously reported, we attempted to determine if peripherally acting benzodiazepine receptor modulators have effects on vascular muscle cells, and if they would interfere with the vasoconstrictor properties of calcium agonists. Because the peripheral-type benzodiazepine binding site is purportedly located on the mitochondrial outer membrane (6), we studied the localization and distribution of intracellular free calcium in addition to vascular contraction. And because porphyrins, as endogenous ligands for the mitochondrial binding site, compete with and displace benzodiazepines (11), interactions between protoporphyrin IX and peripheral benzodiazepines were investigated, and extended to include investigations of guanylate cyclase activity.

\section{Methods}

Isometric tension recording. Wistar-Kyoto (WKY) adult rats that had been etherized and then killed by cervical dislocation were used to provide caudal arteries that were sectioned into $2-\mathrm{mm}$ segments. The segments were placed onto stainless steel stirrups in laminar flow muscle chambers and attached to Akers force transducers for the measurement of isometric tension. The chambers were continuously perfused with ionic solution for mammals (ISM) ${ }^{1}$ consisting of (in millimolar): $130, \mathrm{NaCl} ; 16, \mathrm{NaHCO}_{3} ; 0.5, \mathrm{NaH}_{2} \mathrm{PO}_{4} ; 4.7, \mathrm{KCl} ; 1.8, \mathrm{CaCl}_{2} ; 0.4$, $\mathrm{MgCl}_{2} ; 0.4, \mathrm{MgSO}_{4} ; 13$, Hepes $\left(\mathrm{pH} 7.62\right.$ at $\left.25^{\circ} \mathrm{C}\right)$; and 5.5, dextrose (final pH 7.3-7.4), which was aerated with a $95 \% \mathrm{O}_{2} / 5 \% \mathrm{CO}_{2}$ gas mixture and maintained at a constant temperature of $37^{\circ} \mathrm{C}$. The artery segments were then stretched until a constant resting tension of 600 dyn was attained.

Adrenergic nerve endings were destroyed by an in vitro 6-hydroxydopamine treatment (12). After 90-120 min, the arteries were contracted to a steady state with three exposures to $300 \mathrm{nM}$ norepinephrine. Dose-dependent effects, on contractions induced by $\mathrm{K}^{+}$alone (30 or $100 \mathrm{mM}$ ) or in combination with $\mathrm{Ca}^{2+}$ agonist (SDZ 202-791 [S]), of the peripheral-type benzodiazepine receptor modulators, PK 11195 (1 $\mathrm{nM}$ to $3 \mu \mathrm{M})$ and Ro 5-4864 (1-30 $\mu \mathrm{M})$, were established. Used in conjunction with the PK 11195 and Ro 5-4864 were protoporphyrin IX and the calcium channel agonist, SDZ 202791 (S), and its racemic calcium antagonist, SDZ 202791 (R)(13). To determine the selectiveness of peripheral-type benzodiazepine receptors, Ro 15-1788, a specific central-type benzodiazepine antagonist (14) was also tested. Re-

1. Abbreviations used in this paper: ISM, ionic solution for mammals. 
sulting tension was recorded and analyzed at established time intervals and related to contraction induced by potassium in the presence or absence of the calcium agonist (S), as indicated.

Intracellular calcium quantitation. Primary cultures of vascular muscle cells from azygous veins of 15-20 decapitated neonatal (1-4 d old) WKY rats were prepared as described previously $(15,16)$. After the preparation, the vascular muscle cells were resuspended in CV3 medium and diluted to a density of $70,000 \mathrm{cells} / \mathrm{ml}$ before plating onto poly-L-lysine-coated glass coverslips. The cells were maintained in a $5 \% \mathrm{CO}_{2}$ incubator at $95 \%$ humidity and $37^{\circ} \mathrm{C}$. At least $2 \mathrm{~d}$ after culturing, coverslips were placed in a laminar flow chamber (volume, 300 $\mu l)$ at $37^{\circ} \mathrm{C}(17)$ and a single, spontaneously contracting cell was observed at a magnification of 750 on a Leitz Diavert microscope.

Localization and distribution of intracellular free calcium in a single, fura-2-loaded vascular cell was determined as described in detail elsewhere (18). Briefly, the cells were loaded for $5 \mathrm{~min}$ with a fura-2 solution consisting of $20 \mu \mathrm{l}$ of a stock solution containing $1 \mu \mathrm{M}$ fura-2-acetoxymethylester (19) (in polyethyleneglycol 400: $0.05 \%$ pluronic 127 in DMSO; 1:1), and the extraneous fura- 2 was washed away by ISM. Fluorescence intensity at $510 \mathrm{~nm}$ was detected, with excitation at 340 and $380 \mathrm{~nm}$ as calcium-dependent wavelengths and at $360 \mathrm{~nm}$ as the wavelength close to the isosbestic point. To select appropriate wavelengths, filters $(10 \pm 1 \mathrm{~nm}$ half-height bandwidth; Corion Corp., Holliston, MA) were mounted on a filter holder that allowed for rapid switching. Images were detected and digitized by a high sensitivity, high resolution photon counting camera (VIM) (Photonic Microscopy Inc., Oak Brook, IL) and continuously recorded on a videotape recorder (model VO-5800; Sony Corp. of America, Long Island City, NY). A laser disc (International Scientific Instrument, Inc., Santa Clara, CA) was used for later detailed analysis of the archived images on a computer (Vectra; Hewlett-Packard Co., Palo Alto, CA).

In the experiments of this study, photon (digitized) images were accumulated for $0.25-1 \mathrm{~s}$, from continuous recordings. The following equation was applied to each pixel (image element) individually to determine the apparent calcium activity based on fluorescence: $\mathrm{Ca}^{2+}$ $=K[c(R-1.36) /(3.48-c R)]$ and $c=0.92+2.24 a e^{-(0.0028 d F)}$, where $K$ is the dissociation constant of fura- 2 under our conditions ( $239 \mathrm{nM}), R$ is $340 / 380$ excitation ratio fluorescence, $F$ is the fura- 2 fluorescence intensity count at $360 \mathrm{~nm}, a$ is a correction for daily variability of the lamp and camera, and $d$ is a scaling factor to adjust for accumulation times. This equation represents a best fit of data in 12 different fura- 2 concentrations at 12 different $\mathrm{Ca}^{2+}$ concentrations. The following parameters were analyzed separately in each image: mean intensity/pixel (Ti) of the whole cell, and mean intensity of peripheral areas (within $0.3 \mu \mathrm{m}$ of the surface membrane) and central areas (the remainder).

Guanylate cyclase activity. A fraction containing soluble guanylate cyclase activity was prepared from pig aorta basically as described for bovine lung (20). Pig aorta medial layers were homogenized at $4^{\circ} \mathrm{C}$ in 5 vol of $25 \mathrm{mM}$ triethylammonium, pH 7.8 (in a Polytron [model PTA 20S]; Kinematica, Lucerne, Switzerland; four times/s with setting 7). The homogenate was centrifuged first for $10 \mathrm{~min}$ at $43,000 \mathrm{~g}$ and then for $1 \mathrm{~h}$ at $100,000 \mathrm{~g}$. To the final supernatant, $5 \mathrm{mM}$ DTT was added. This material was used within $2 \mathrm{~h}$ for the experiments. Guanylate cyclase activity was measured in triplicates and each experiment was repeated at least three times. Samples containing $10 \mu \mathrm{l}$ of biological material and $200 \mu \mathrm{l}$ of buffer $(100 \mu \mathrm{M}$ isobutyl methylxanthine, $3 \mathrm{mM}$ $\mathrm{MgCl}_{2}, 40 \mathrm{mM}$ Tris [pH 7.4]) were preincubated in the presence of either drugs or solvent (DMSO, final concentration $1 \%$ ) at $37^{\circ} \mathrm{C}$ for 2 min. The reaction was started by the addition of $1 \mathrm{mM} \mathrm{GTP}$ and stopped after $10 \mathrm{~min}$ by the addition of $20 \mathrm{mM}$ ice-cold EDTA. Production of CGMP was determined using a cGMP RIA kit (Amersham Corp., Arlington Heights, IL).

Statistics. Results are presented as mean \pm SEM based on 5-12 experiments. Means were compared using paired or unpaired $t$ tests and Wilcoxon tests for matched pairs, dependent on the experimental procedure. A value of $P<0.05$ was accepted as significantly different.

Materials. PK 11195 was kindly provided by Rhone-Poulenc, Gennevilliers, France; Ro 15-1788 was a gift from Prof. Haefely,
Hoffmann-La Roche Pharmaceuticals, Basel, Switzerland; the enantiomers of the calcium channel agonist and antagonist pair (SDZ 202-791) were from Dr. Hof, Sandoz Pharmaceuticals, Basel, Switzerland; and the phosphor beads were provided by Sylvania GTE Products Co., Towanda, PA. All other compounds used were obtained commercially.

\section{Results}

PK 11195 (3 $\mu \mathrm{M})$, Ro 5-4864 (30 $\mu \mathrm{M})$, Ro 15-1788 (30 $\mu \mathrm{M})$, and protoporphyrin IX $(1 \mu \mathrm{M})$ had no effect on resting tension up to the highest concentrations tested in these experiments. In contrast, addition of $\mathrm{K}^{+}(30$ or $100 \mathrm{mM})$ either in the presence or absence of the calcium channel agonist, SDZ 202-791 (S), (from $10 \mathrm{nM}$ to $1 \mu \mathrm{M}$ ) caused reliable contractions of caudal arteries. In $100-\mathrm{mM} \mathrm{K}^{+}$solutions, there was an initial phasic contraction within $20 \mathrm{~s}$ of drug arrival, followed by a submaximal tonic contraction, whereas $30 \mathrm{mM} \mathrm{K}{ }^{+}$caused a contraction without a phasic portion that developed over $2 \mathrm{~min}$ and was maintained or increased until return to ISM (Fig. 1). Effects of these benzodiazepine modulators on phasic (1-3', peak) and tonic (at $10^{\prime}$ ) portions of contractions during continuous perfusion in $\mathrm{K}^{+}$stimulating solutions were dose-dependent and summarized in Table $I$ at the highest doses of drugs tested. These concentration dependent effects are most clearly evident in Figs. 2 and 3 for either Ro 5-4864 or PK 11195 on tonic contractions induced by $\mathrm{K}^{+}$or $\mathrm{K}^{+}$plus $\mathrm{Ca}^{2+}$ channel agonist.

In the presence of either Ro 5-4864 (1-30 $\mu \mathrm{M})$ or PK $11195(10 \mathrm{nM}$ to $3 \mu \mathrm{M})$, a concentration-dependent reduction of tonic contractions induced by $\mathrm{K}^{+}$or $\mathrm{K}^{+}$plus calcium agonist was observed (Fig. 1, Table I). The phasic contraction was reduced only at the higher concentrations investigated for Ro 5-4864 and PK 11195. The reduction of vasoconstriction by benzodiazepine receptor-modulating drugs was not different, whether contractions had been induced by $\mathrm{K}^{+}$alone or by combinations of $\mathrm{K}^{+}$and the calcium agonist (Table I). Effects of PK 11195 on contractions induced by $100 \mathrm{mM} \mathrm{K}^{+}$are presented in Fig. 2 where, in the presence of $3,000 \mathrm{nM}$ PK 11195 , tonic contraction was reduced to $12 \pm 4 \%$ and phasic contraction was reduced to $44 \pm 3 \%\left(100 \mathrm{mM} \mathrm{K}^{+}\right.$as $100 \%, n$ $=15, P<0.05)$. No alteration of the percent reduction was

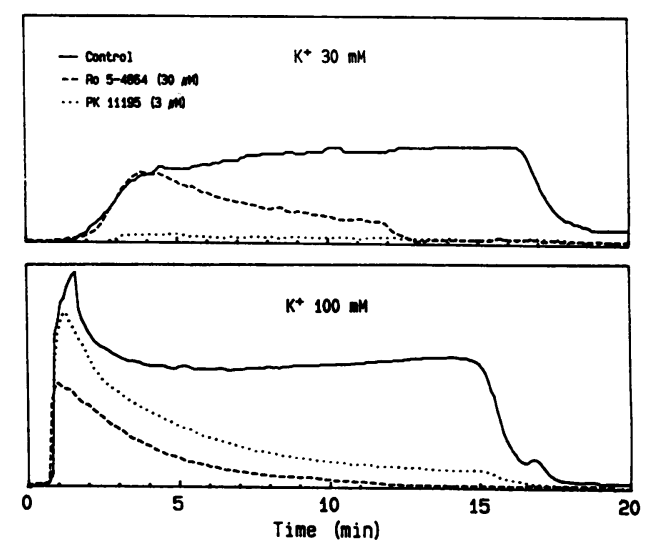

Figure 1. Effect of $30 \mu \mathrm{M}$ Ro 5-4864 and $3 \mu \mathrm{M}$ PK 11195 on $\mathrm{K}^{+}$-induced contractions (stimulated by $\mathrm{K}^{+}$at 30 or $100 \mathrm{mM}$ with $100 \mathrm{nM}$ SDZ 202-791 [S]). Records represent rat caudal artery segment responses to the benzodiazepine receptor-modulating drugs. Return to control (ISM) solution was at $15 \mathrm{~min}$. 
Table I. Vasodilator Actions of Peripheral Benzodiazepine Receptor-modulating Drugs

\begin{tabular}{lcc}
\hline \multicolumn{1}{c}{ Solution } & $\begin{array}{c}\text { Phasic tension } \\
\text { (first } 3 \text { min) }\end{array}$ & $\begin{array}{c}\text { Tonic tension } \\
\text { (at 10 min) }\end{array}$ \\
\hline & \multicolumn{2}{c}{$d y n$} \\
ISK $(30)$ & 310 & 340 \\
ISK $(100)$ & 970 & 620 \\
ISK $(30)+$ S & 345 & 380 \\
ISK $(100)+$ S & 980 & 960 \\
ISK $(100)+$ S + Ro 15-1788 & 985 & 950 \\
ISK $(100)+$ S + P IX & 970 & 950 \\
ISK $(100)+$ S + PK 11195 & 820 & $210^{*}$ \\
ISK $(100)+$ S + Ro 5-4864 & $480^{*}$ & $170^{*}$ \\
ISK $(100)+$ S + PK 11195 + P IX & $460^{* \ddagger}$ & $200^{*}$ \\
ISK $(100)+$ S + Ro 5-4864 + P IX & $160^{* \ddagger}$ & $140^{* \ddagger}$ \\
& & \\
\hline
\end{tabular}

ISK is an ionic solution similar to ISM, but with potassium altered to the indicated millimolar value. PK $11195,1 \mu \mathrm{M}$; Ro 5-4864, 30 $\mu \mathrm{M}$. P IX, protoporphyrin IX at $1 \mu \mathrm{M}$; Ro 15-1788, $30 \mu \mathrm{M}$. S, SDZ 202-791 (S) at $100 \mathrm{nM}$. All values are means of 4-12 experiments. SEMs were $5-10 \%$ of means.

* Significant differences from the ISK $(100)+\mathrm{S}$ reference value (in the corresponding column).

${ }^{\ddagger}$ Differences of $\mathrm{P}$ IX solutions from corresponding means without $\mathrm{P}$ IX.

observed if the SDZ $\mathrm{Ca}^{2+}$ channel agonist was present in addition to $\mathrm{K}^{+}$. Effects of Ro 5-4864 were less potent, especially on phasic contraction (Fig. 3). Ro 15-1788 (the central type benzodiazepine drug) and protoporphyrin IX alone were ineffective upon resting tension or contraction induced by $\mathrm{K}^{+}$or $\mathrm{K}^{+}$ plus calcium agonist (Table I). However, although protoporphyrin up to $1 \mu \mathrm{M}$ had no effect on tension, whether resting or stimulated, the combination of $1 \mu \mathrm{M}$ protoporphyrin IX and Ro 5-4864 reduced both phasic and tonic contraction to $\sim 10 \%$ of controls (Fig. 3). Similarly, in the presence of protoporphyrin IX, the same concentrations of PK 11195 were more effective (Fig. 4). However, the combination of PK 11195 and Ro 5-4864 gave no additional reduction beyond that of either drug alone.

We noted that protoporphyrin IX $(5-1,000 \mathrm{nM})$ together with Ro 5-4864 (3-30 $\mu \mathrm{M})$ caused the largest reduction in

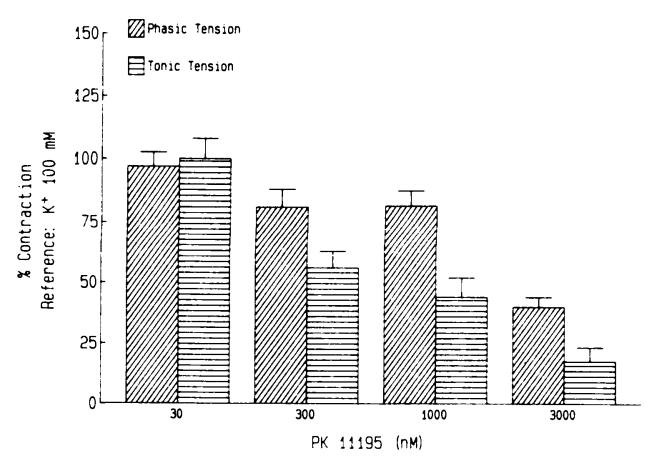

Figure 2. Effect of PK 11195 on $\mathrm{K}^{+}(100 \mathrm{mM})$ with $100 \mathrm{nM} \mathrm{SDZ}$ 202-791 (S)-induced contraction. The tonic part of contraction was preferentially reduced at all PK 11195 concentrations. Mean \pm SEM, $n=11$.

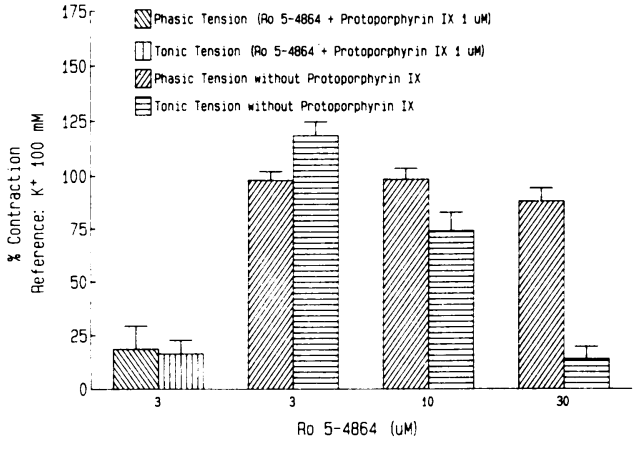

Figure 3. Relaxation by Ro $5-4864$ of $\mathrm{K}^{+}$with $100 \mathrm{nM}$ agonist (SDZ 202-791 [S]) contractions, and effect of protoporphyrin IX. Without protoporphyrin IX, Ro 5-4864 blocked only the maintained tonic phase of contraction and only at higher concentrations. Protoporphyrin IX markedly potentiated the relaxant effect of Ro 5-4864, especially against phasic contractions. Protoporphyrin IX potentiated the relaxant effect of Ro 5-4864 more than any other compound studied to date. Mean \pm SEM of 12 experiments.

contraction stimulated by $\mathrm{K}^{+}$or $\mathrm{K}^{+}$plus agonist observed, and caused effective relaxation even at lower concentrations ( $0.5-3$ $\mu \mathrm{M}$ ) of Ro 5-4864 (Fig. 3). The most impressive feature of the enhanced vasorelaxant action with protoporphyrin IX was that phasic contraction, which had not been reduced by even higher Ro 5-4864 concentration without protoporphyrin, was reduced even at submaximal concentrations of Ro 5-4864 protoporphyrin (Fig. 3).

The inhibition of initial and later phases of contraction induced by $\mathrm{K}^{+}$, or $\mathrm{K}^{+}$with calcium agonist, is characteristic of calcium channel antagonists. We therefore investigated the effects of the benzodiazepine-modulating drugs, Ro 5-4864 and PK 11195, in the presence of $30 \mathrm{nM}$ of the calcium channel antagonist SDZ 202-791 (R), a weakly effective concentration. Used alone, SDZ 202-791 (R) reduced phasic and tonic tension stimulated by $\mathrm{K}^{+}$alone or in combination with SDZ 202-791 (S). The effects of the $\mathrm{Ca}^{2+}$ antagonist on phasic contraction were not the same for Ro 5-4864 and PK 11195. Although the calcium antagonist ( $\mathrm{R}$ isomer) in combination with Ro 5-4864, or PK 11195, resulted in a reduction of tonic tension, there was a potentiation of phasic portions of contraction in the presence of Ro 5-4864. The reduction of tonic

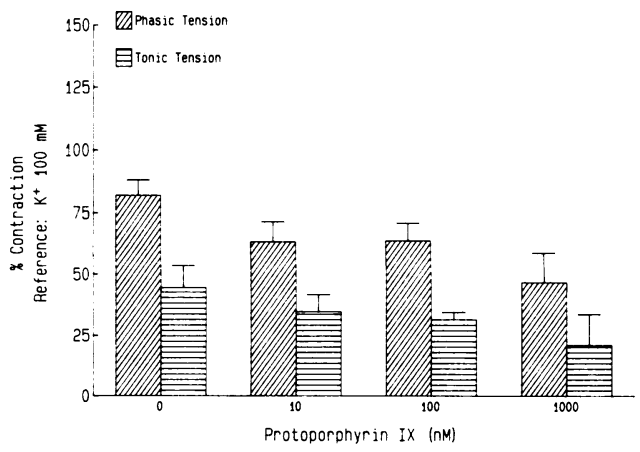

Figure 4. Relaxation of $100 \mathrm{mM} \mathrm{K}^{+}$plus $\mathrm{Ca}^{2+}$ agonist (100 nM SDZ 202-791 [S]) contractions by $100 \mathrm{nM}$ PK 11195 was potentiated by protoporphyrin IX. Tonic tension was decreased, even without protoporphyrin IX, but the relaxations were always greater with protoporphyrin IX than without. Means \pm SEM, $n=12$. 


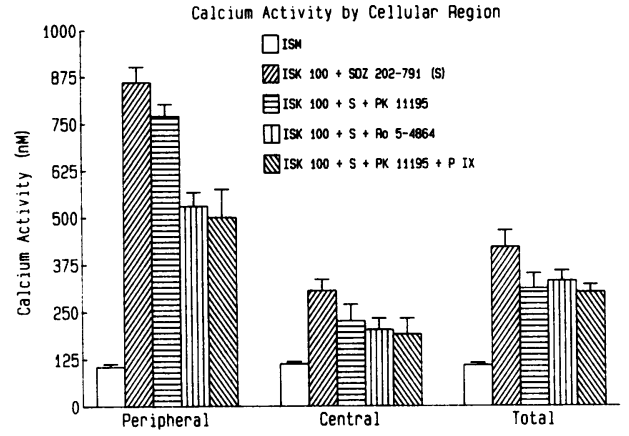

Figure 5. Reduction of intracellular $\mathrm{Ca}^{2+}$ activity (free ion concentration in nanomolar) by PK $11195(1 \mu \mathrm{M})$ and Ro 5-4864 $(30 \mu \mathrm{M})$ was marked in both central and peripheral regions, but more pronounced effects always were at the periphery. Values represent means of 7-25 experiments on different cells $(n=22-148)$. Standard errors for each mean are shown. Increases of $\mathrm{Ca}^{2+}$ by ISK 100 with SDZ 202-791 (S) (100 nM) were significant in peripheral, central, and total regions. Decreases in $\mathrm{Ca}^{2+}$ activity by $\mathrm{Ro} 5-4864$ or PK 11195 with or without P IX (protoporphyrin IX, $10 \mathrm{nM}$ ) were significant in all three (peripheral, central, and total) regions. Protoporphyrin IX enhanced the $\mathrm{Ca}^{2+}$ decrease by PK 11195 in both central and peripheral areas, which was only evident at later time points (than the 15-30 s after drug arrival) shown here.

contraction was less than that found with either Ro 5-4864 or SDZ 202-791 (R) alone, suggesting interference of these two drugs with each other.

Benzodiazepine-modulating drugs reduced intracellular free $\mathrm{Ca}^{2+}$ activity in $\mathrm{K}^{+}$or $\mathrm{K}^{+}$plus calcium channel agonist solutions, with predominant decreases in the $\mathrm{Ca}^{2+}$ release regions of the cell (Fig. 5). The decrease in $\mathrm{Ca}^{2+}$ occurred on arrival of the combination of drugs, and was potentiated by protoporphyrin IX. Decreases in $\mathrm{Ca}^{2+}$ activity were observed in both peripheral and central regions, and potentiation of $\mathrm{Ca}^{2+}$ activity decreases by protoporphyrin IX were more pronounced in every case at the cell periphery than in the central regions. Total cell $\mathrm{Ca}^{2+}$ activity decreased by less, as only $\sim 25 \%$ of the cell was represented by areas of $\mathrm{Ca}^{2+}$ release.

The effect of Ro 5-4864 and of protoporphyrin IX on a soluble guanylate cyclase fraction obtained from pig aortic muscle homogenates was investigated to further explore subcellular mechanisms. In the presence of the benzodiazepine (up to $300 \mu \mathrm{M}$ ), only very marginal and inconsistent stimulatory effects of the enzyme activity could be detected, in contrast to investigations on guanylate cyclase prepared from pig lung where a consistent stimulation of guanylate cyclase activity by Ro 5-4864 could be observed (unpublished observations). On the other hand, protoporphyrin IX stimulated the soluble guanylate cyclase consistently. Under our assay conditions, the enzyme from pig aorta was stimulated by the heme four to fivefold with an $\mathrm{EC}_{50}$ of $56 \mathrm{nM}$ (not shown). The benzodiazepine displayed no additional stimulatory effect on the guanylate cyclase when tested in the presence of optimal concentrations of protoporphyrin (i.e., $1 \mu \mathrm{M}$ ). Interestingly, however, Ro 5-4864 was found to stimulate cGMP production when tested in the presence of protoporphyrin IX at low concentrations (i.e., 4-10 nM) which are just above the threshold for activation (Fig. 6). The enzyme activity was then found to be increased by $40-60 \%$ even at submicromolar concentrations of Ro 5-4864.

\section{Discussion}

The results of this study demonstrate for the first time that the peripheral-type benzodiazepine-modulating drugs have vasodilator properties. We have also discovered the powerful enhancement of the vasodilation by the endogenous substance, protoporphyrin IX. This vasodilation is most likely due to interaction with a peripheral-type benzodiazepine receptor. Vasodilation by PK 11195 was observed only at concentrations $>10 \mathrm{nM}$, which is higher than that needed in receptor binding studies $(6,21)$. The higher concentrations for vasodilation may have several causes. Differences in postreceptor mechanisms might be one explanation (although unlikely), and the lower sensitivity of whole organ preparations than single cells or cell fractions might be another (17). Alternatively and more likely, the binding site in vascular muscle may have a lower affinity, comparable to that of certain other cells (nerve terminals) (22).

In this study on caudal arteries, both benzodiazepine-modulating drugs not only reduced the phasic contraction induced by $\mathrm{K}^{+}$, but also reversed the additional contraction during the tonic phase with or without calcium agonist. In a study on cardiac muscle, Mestre et al. (7) observed that the effects of Ro 5-4864 on the promotion of slow action potentials induced by $\mathrm{Ca}^{2+}$ agonists was inhibited by high concentrations of PK 11195 (9). In contrast, no mutually opposing actions of PK 11.195 and Ro 5-4864 were observed in the caudal artery. However, in the presence of the calcium channel antagonist, relaxant effects of Ro 5-4864 and PK 11195 on the tonic contraction were reduced. Furthermore, relaxant effects of PK 11195 and Ro 5-4864 on phasic tension were potentiated in the presence of the $\mathrm{Ca}^{2+}$ antagonist. These results suggest that the phasic and tonic phases of contraction might be regulated by different mechanisms governing multiple sources of $\mathrm{Ca}^{2+}$. Peripheral-type benzodiazepine modulators may be useful in resolving these underlying processes. On the other hand, the central-type benzodiazepine modulator, Ro 15-1788, failed to cause relaxation. Inactivity of the central-type benzodiazepine modulator might have been anticipated, as only the peripheral type is present before birth; the central-type appears to be fully active after birth (1).

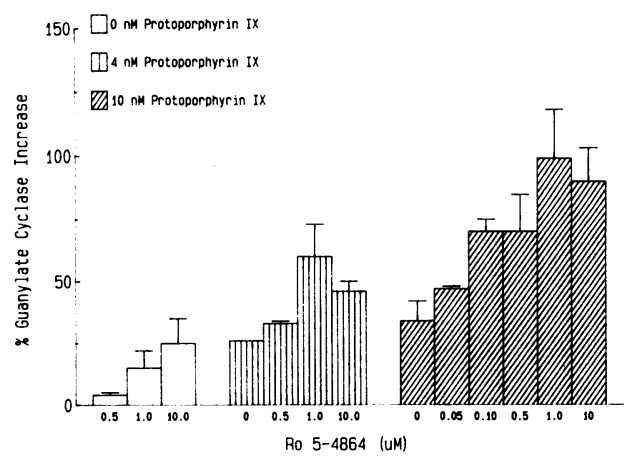

Figure 6. Soluble guanylate cyclase was stimulated by Ro 5-4864, and the increase was amplified by protoporphyrin IX, which increased activity alone as well, in pig aorta extractions. Cell homogenates were exposed to drugs for $2 \mathrm{~min}$, then the reaction was run for $10 \mathrm{~min}$ and CGMP was determined. Values are means \pm SEM of three to four experiments. Increases by Ro 5-4864 in both concentrations of protoporphyrin IX are significant based on a Wilcoxon test for matched pairs. 
In this study, we have restricted our investigations to protoporphyrin IX. However, it has been reported that other porphyrins do also bind, although less, to the same ligand as protoporphyrins IX (11). Erythrocytes are the major physiological source of protoporphyrin IX, which when it is released is metabolized to the other porphyrins. Although in plasma from blood donors, protoporphyrin IX is present at concentrations $<2.5 \mathrm{nM}(23,24)$, this idea could be of potential therapeutic importance for the observed vasodilatory effects of benzodiazepine modulators, because in some clinical conditions, associated anemias in chronic disorders, liver disease, intoxications, and in patients with hemolysis after heart valve replacement, porphyrins are markedly elevated $(23,25)$, reaching levels up to $2 \mu \mathrm{M}$ in patients with erythropoietic protoporphyria (23).

One of the features reported for high-affinity, peripheral benzodiazepine receptors is that porphyrins are its endogenous ligands (11), and that an opposite action (interference with vasodilation) might be predicted when benzodiazepines were added to porphyrins, such as protoporphyrin IX, used in this study due to its high affinity for the peripheral benzodiazepine receptor. In contrast to this hypothesis, we detected a marked potentiation of the relaxant effects of both Ro 5-4864 and PK 11195 on the sustained phase of contraction by protoporphyrin IX. Furthermore, and most significantly, we discovered that Ro 5-4864 and PK 11195 in conjunction with protoporphyrin IX were able to reduce both phasic and tonic contraction (even though protoporphyrin IX alone had no effect on tension). This idea is of potential therapeutic importance for the observed vasodilatory effects of benzodiazepines and their use in clinical conditions which lead to increased porphyrin concentrations in blood.

Considering that Ro 5-4864 and PK 11195 reduce contractions induced by $\mathrm{K}^{+}$and $\mathrm{Ca}^{2+}$ channel agonist, and that peripheral benzodiazepine receptors to which porphyrins bind are located on the mitochondrial outer membrane $(6,11)$, it was of interest to investigate their possible effects on intracellular calcium distribution. Areas of high calcium concentration (hot spots) were detected using a highly sensitive photoncounting camera and fura-2. In separate studies $(18,26)$, we have concluded that hot spots were not due to inhomogeneous fura-2 distribution. We believe that these hot spots must be due to local intracellular calcium release or uptake resulting in steep local calcium gradients. These hot spots increase in number and size after the administration of $\mathrm{K}^{+}$and even more in the presence of the $\mathrm{Ca}^{2+}$ channel agonist, contributing the major part of the increase in mean cell $\mathrm{Ca}^{2+}$. In particular, an increase in $\mathrm{Ca}^{2+}$ in central areas was observed, as $\mathrm{Ca}^{2+}$ was released from centrally located pools. Ro 5-4864 and PK 11195 , however, lead to a decrease in central $\mathrm{Ca}^{2+}$ and to a smaller extent peripheral $\mathrm{Ca}^{2+}$ in sarcolemmal zones.

A further interesting finding of this study is the activation of the soluble guanylate cyclase by the concerted action of protoporphyrin IX and the peripheral-type benzodiazepine Ro 5-4864. A series of circumstances drew our attention on the soluble guanylate cyclase as a possible molecular target: $(a)$ the enzyme plays notably a key role in the relaxation of smooth muscles; and (b) its activity is known to be regulated by an endogenous heme (27); and to be stimulated by exogenous protoporphyrin IX (28). In analogy to the mitochondrial benzodiazepine receptor which also interacts with porphyrins (11), it is attractive to imagine that the benzodiazepines can directly interact with (and stimulate) porphyrin binding by guanylate cyclase, thus providing a possible molecular mechanism for their vasodilating effect.

In this study, however, micromolar concentrations of protoporphyrin IX, which maximally stimulate the isolated soluble guanylate cyclase fraction, had no vasodilatory action (see Table I). The lack of effect can be explained by the absence of specific transport mechanisms at the plasma membrane to facilitate the penetration of the heme into the cells. Very likely, the intracellular concentration of protoporphyrin IX during the contraction experiments was not sufficient to cause any relevant stimulation of the cyclase activity. On the other hand, it is under such conditions of suboptimal heme concentrations that the benzodiazepine Ro 5-4864 can exert its stimulatory activity on the enzyme. Fig. 6 shows that a synergistic stimulation of the CGMP production can be obtained by the concerted interplay of Ro 5-4864 and of protoporphyrin IX.

The detailed study of the intracellular distribution of $\mathrm{Ca}^{2+}$ presented in Fig. 5 shows that Ro 5-4864 and protoporphyrin IX interfere more prominently with the mobilization of intracellular $\mathrm{Ca}^{2+}$ in the central regions of the cell than in the subsarcolemmal zones. This observation is also compatible with a mechanism of action involving cGMP. In rat aorta, indeed, cGMP was shown to interfere mostly with the intracellular activation of $\mathrm{Ca}^{2+}$, whereas $\mathrm{Ca}^{2+}$-influx is less affected (29). cGMP antagonism of intracellular $\mathrm{Ca}^{2+}$ elevation could depend on the stimulation of intracellular $\mathrm{Ca}^{2+}$-sequestration or binding systems. Interestingly, a recent study has provided evidence for the stimulation of the $\mathrm{Ca}^{2+}$-pumping activity of the sarcoplasmic reticulum in smooth muscle by the cGMPdependent phosphorylation of phospholamban (30).

In conclusion, drugs interacting with peripheral-type benzodiazepine receptors cause a vasodilation, accompanied by a reduction of intracellular $\mathrm{Ca}^{2+}$ release or a stimulation of intracellular $\mathrm{Ca}^{2+}$ uptake. This newly described action of benzodiazepines is strongly potentiated by protoporphyrins, possibly by amplified mechanisms at the site of action. A possible mechanism of action could be through cGMP-dependent pathways. Furthermore, these putative benzodiazepine-modulating drugs interfered with direct calcium channel stimulation, suggesting the need for more investigation of their role as modulators of the calcium channel.

\section{Acknowledgments}

This study was supported by National Institutes of Health grants HL-38537 and HL-38645 and by the Schweizerische Stiftung fur Kardiologie. P. Erne was supported by the Schweizerische Stiftung fur Medizinische-Biologische Stipendien.

\section{References}

1. Anholt, R. R. H. 1986. Mitochondrial benzodiazepine receptors as potential modulators of intermediary metabolism. Trends Pharmacol. Sci. 506-511.

2. Moehler, H., and T. Okada. 1977. Properties of 3H-diazepam binding to benzodiazepine receptors in rat cerebral cortex. Science (Wash. DC). 198:849-857.

3. Wang, J. K. T., J. I. Morgan, and S. Spector. 1984. Differentiation of friend erythroleukemia cells induced by benzodiazepines. Proc. Natl. Acad. Sci. USA. 81:3770-3772.

4. Anholt, R. R. H., U. Aebi, P. L. Pederson, and S. H. Snyder. 1986a. Solubilization and reassembly of the mitochondrial benzodiazepine receptor. Biochemistry. 25:2120-2125. 
5. Zavala, F., J. Haumont, and M. Lenfant. 1985. Interaction of benzodiazepines with mouse macrophages. Eur. J. Pharmacol. 106:561-566.

6. Anholt, R. R. H., P. L. Pedersen, E. B. De Souza, and S. H. Snyder. 1986. The peripheral-type benzodiazepine receptor: Localization to the mitochondrial outer membrane. J. Biol. Chem. 261:576583.

7. Mestre, M., T. Carriot, C. Belin, A. Uzan, C. Renault, M. C. Dubroeucq, C. Gueremy, and G. Le Fur. 1984. Electrophysiological and pharmacological characterization of peripheral benzodiazepine receptors in a guinea pig heart preparation. Life Sci. 35:953-962.

8. Doble, A., J. Benavides, O. Ferris, P. Betrand, J. Menager, N. Vaucher, M. Burgevin, A. Uzan, C. Gueremy, and G. Le Fur. 1985. Dihydropyridine and peripheral type benzodiazepine binding sites: subcellular distribution and molecular size determination. Eur. $J$. Pharmacol. 119:153-167.

9. Mestre, M., T. Carriot, G. Neliat, A. Uzan, C. Renault, M. C. Dubroeucq, C. Gueremy, A. Doble, and G. Le Fur. 1986. PK 11195, an antagonist of peripheral type benzodiazepine receptors, modulates BAY K8644 sensitive but not beta- or $\mathrm{H} 2$-receptor sensitive voltage operated calcium channels in the guinea pig heart. Life Sci. 39:329339.

10. Holck, M., and W. Osterrieder. 1985. The peripheral, high affinity benzodiazepine binding site is not coupled to the cardiac $\mathrm{Ca}^{++}$ channel. Eur. J. Pharmacol. 118:293-301.

11. Verma, A., J. S. Nye, and S. H. Snyder. 1987. Porphyrins are endogenous ligands for mitochondrial (peripheral-type) benzodiazepine receptor. Proc. Natl. Acad. Sci. USA. 84:2256-2260.

12. Aprigliano, O., and K. Hermsmeyer. 1976. In vitro denervation of the portal vein and caudal artery of the rat. J. Pharmacol. Exp. Ther. 198:578-587.

13. Hof, R. P., U. T. Ruegg, A. Hof, and A. Vogel. 1985. Stereoselectivity at the calcium channel: opposite action of the enantiomers of a 1,4-dihydropyridine. J. Cardiovasc. Pharmacol. 7:689-693.

14. Hunkeler, W., H. Moehler, L. Pieri, P. Polc, E. P. Bonetti, R. Cumin, R. Schaffner, and W. Haefely. 1981. Selective antagonists of benzodiazepines. Nature (Lond.). 290:514-516.

15. Marvin, W., R. Robinson, and K. Hermsmeyer. 1979. Correlation of function and morphology of neonatal rat embryonic chick cultured cardiac and vascular cells. Circ. Res. 45:528-540.

16. Hermsmeyer, K., and R. Mason. 1982. Norepinephrine sensitivity and desensitization of cultured single vascular muscle cells. Circ. Res. 50:627-632.

17. Hermsmeyer, K., and R. Robinson. 1977. High sensitivity of cultured cardiac muscle cells to autonomic agents. Am. J. Physiol. 233:C172-C179.
18. Erne, P., and K. Hermsmeyer. 1988. Desensitization to norepinephrine includes refractoriness of calcium release in myocardial cells. Biochem. Biophys. Res. Commun. 151:333-338.

19. Grynkiewicz, G., M. Poenie, and R. Y. Tsien. 1985. A new generation of $\mathrm{Ca}^{2+}$ indicators with greatly improved fluorescence properties. J. Biol. Chem. 260:3440-3449.

20. Wolin, M. S., K. S. Wood, and L. J. Ignarro. 1982. Guanylate cyclase from bovine lung. A kinetic analysis of the regulation of the purified soluble enzyme by protoporphyrin IX, heme, and nitrosylheme. J. Biol. Chem. 257:13312-13320.

21. Anholt, R. R. H., E. B. De Souza, M. R. Oster-Granite, and S. H. Snyder. 1985. Peripheral-type benzodiazepine receptors: Autoradiographic localization in whole-body section of neonatal rats. $J$. Pharmacol. Exp. Ther. 233:517-526.

22. Taft, W. C., and R. T. DeLorenzo. 1984. Micromolar-affinity benzodiazepine receptors regulate voltage-sensitive calcium channels in nerve terminal preparations. Proc. Natl. Acad. Sci. USA. 81:401408.

23. van Gog, H., and A. A. Schothorst. 1973. Determination of very small amounts of protoporphyrin in epidermis, plasma, and blister fluids. J. Invest. Dermatol. 61:42-45.

24. With, T. K. 1977. Porphyrins in erythrocytes and blood plasma: preliminary studies with qualitative thin-layer chromatography. Clin. Sci. Mol. Med. 52:463-467.

25. Lamon, J. M. 1977. Clinical aspects of porphyrin measurement, other than lead poisoning. Clin. Chem. 23:260-263.

26. Erne, P., and K. Hermsmeyer. 1988. Intracellular $\mathrm{Ca}^{++}$release in vascular muscle cells by caffeine, ryanodine, norepinephrine, and neuropeptide Y. J. Cardiovasc. Pharmacol. 12(Suppl. 5):S85-S91.

27. Ignarro, L. J., J. N. Degnan, W. H. Baricos, P. J. Kadowitz, and M. S. Wolin. 1982. Activation of purified guanylate cyclase by nitric oxide requires heme. Comparison of heme-deficient, heme-reconstituted and heme-containing forms of soluble enzyme from bovine lung. Biochim. Biophys. Acta. 718:49-59.

28. Ignarro, L. J., K. S. Wood, and M. S. Wolin. 1982. Activation of purified soluble guanylate cyclase by protoporphyrin IX. Proc. Natl. Acad. Sci. USA. 79:2870-2973.

29. Lincoln, T. M., 1983. Effects of nitroprusside and 8-bromo-cyclic GMP on the contractile activity of the rat aorta. J. Pharmacol. Exp. Ther. 224:100-107.

30. Raeymaekers, L., F. Hofmann, and R. Casteels. 1988. Cyclic GMP-dependent protein kinase phosphorylates phospholamban in isolated sarcoplasmic reticulum from cardiac and smooth muscle. Biochem. J. 252:269-273. 